\title{
Influence of wild-type MLL on glucocorticoid sensitivity and response to DNA-damage in pediatric acute lymphoblastic leukemia
}

\author{
Alex H Beesley ${ }^{1}$, Janelle L Rampellini ${ }^{1}$, Misty-Lee Palmer ${ }^{1,3}$, Jasmin YS Heng ${ }^{1}$, Amy L Samuels ${ }^{1}$, Martin J Firth², \\ Jette Ford ${ }^{1}$, Ursula R Kees ${ }^{1 *}$
}

\begin{abstract}
Background: Rearrangement of the mixed-lineage leukemia gene (MLL) is found in $80 \%$ of infant acute lymphoblastic leukemia (ALL) and is associated with poor prognosis and resistance to glucocorticoids (GCs). We have recently observed that GC resistance in T-ALL cell lines is associated with a proliferative metabolism and reduced expression of $M L L$. In this study we have further explored the relationship between $M L L$ status and GC sensitivity.

Results: Negative correlation of MLL expression with GC resistance in 15 T-ALL cell lines was confirmed by quantitative RT-PCR. The absence of MLL-rearrangements suggested that this relationship represented expression of wild-type MLL. Analysis of MLL expression patterns revealed a negative relationship with cellular metabolism, proliferation and anti-apoptotic transcriptional networks. In silico analysis of published data demonstrated that reduced levels of MLL MRNA are associated with relapse and prednisolone resistance in T-ALL patients and adverse clinical outcome in children with MLL-rearranged ALL. RNAi knockdown of MLL expression in T-ALL cell lines significantly increased resistance to dexamethasone and gamma irradiation indicating an important role for wildtype $M L L$ in the control of cellular apoptosis.
\end{abstract}

Conclusions: The data suggests that reduced expression of wild-type MLL can contribute to GC resistance in ALL patients both with and without MLL-translocations.

\section{Background}

Among pediatric subtypes of acute lymphoblastic leukemia (ALL), infants and those with T-lineage ALL are particularly resistant to glucocorticoids (GCs), one of the most important classes of drug for this disease [1]. Rearrangement of the mixed lineage leukemia gene $(M L L)$ gene affects $80 \%$ of ALL in infants and is associated with a particularly poor prognosis [2,3]. $M L L$ is located at $11 \mathrm{q} 23$ and encodes a histone methyltransferase that through its regulation of $H O X$ genes is essential for normal mammalian development and hematopoiesis [4]. A unique feature of the $M L L$ locus is that it is subject to an extremely wide variety of rearrangements,

\footnotetext{
* Correspondence: labadmin@ichr.uwa.edu.au

'Division of Children's Leukaemia and Cancer Research, Telethon Institute for Child Health Research, University of Western Australia Centre for Child Health Research, Perth, Australia

Full list of author information is available at the end of the article
}

including translocations with $>50$ partner genes on various chromosomes, as well as deletions, inversions, internal duplications and gene amplifications [4-6]. There are conflicting reports on the relative GC responses of patients with different $M L L$ translocations $[7,8]$, but those with $t(4 ; 11)$ translocations appear particularly resistant $[3,8,9]$. The biological basis for the documented GC resistance of patients with $M L L$-disease has not been explored but has generally been assumed to be due to the oncogenic effects of translocated $M L L$ fusion proteins.

Despite the clinical importance of GCs for the treatment of ALL, detailed knowledge about the transduction pathways leading to GC-induced apoptosis in lymphoid tissues remains limited [10]. Recently we performed transcriptional profiling of a panel of T-ALL cell lines and reported that GC resistance was associated with a proliferative metabolism [11]. We also observed that GC 
resistance profiles were significantly correlated with reduced expression of $M L L$. In this study we have further investigated the relationship between $M L L$ expression and GC sensitivity in T-ALL and provide evidence that it is the wild-type expression of the gene, rather than the effect of translocations, that appears to be critical for determining a resistant phenotype. This novel finding may help to explain why GC-resistance is a common feature of most patients with $M L L$-disease despite the wide variety of possible gene rearrangements

\section{Methods}

\section{Cell lines and drug sensitivity profiling}

The cell line panel has been previously described and comprised nine T-ALL lines derived in our own laboratory from pediatric ALL bone marrow specimens (PER cell lines), plus six additional T-ALL cell lines obtained from external sources $[12,13]$. Cell lines were grown in RPMI-1640 supplemented with $2 \mathrm{mM}$ L-glutamine, 10 nM 2-mercaptoethanol and 10-20\% heat-inactivated fetal calf serum. The media for PER-cell lines contained additional non-essential amino acids and pyruvate, whilst 300 units $/ \mathrm{ml}$ interleukin-2 is required for growth of PER-427 and PER-487. The sensitivity of the T-ALL cell lines to methylprednisolone (MPRED) and dexamethasone (DEX) has been previously published [12] and was measured using the MTT assay with drugs incubated over four days. The IC50 (drug concentration that inhibits cell growth by $50 \%$ ) was used as the measure of drug resistance.

\section{Gene Expression Profiling}

Briefly, RNA was extracted from cell lines in exponential growth phase and hybridized to Affymetrix HG-U133A microarrays $[11,14]$. Microarray data were normalized using robust multi-array analysis (RMA) and all passed quality control criteria for noise, background, absent/present calls, and 3'/5' signal ratios for ACTB and GAPDH. To interrogate the biological pathways represented by $M L L$ expression profiles we used Gene Set Enrichment Analysis (GSEA) [15]. The median value of the five $M L L$ probe sets present on the HG-U133A was calculated for each cell line, and correlated across the panel against all other probe sets on the array using Pearson's correlation as metric (GSEA v2.0, May 2006, 10,000 permutations). GSEA examines ranked lists of genes for enrichment of biological pathways contained within four different databases: C1 (genomic loci), C2 (curated biological pathways), C3 (genes with common regulatory motifs), and C4 (computational gene networks). Since not all genes within a given biological pathway are expected to be regulated in the same direction, rankings were performed using absolute correlation values as previously described [11]. Published microarray data used for in silico analysis
[14,16-18] was downloaded from publicly available depositories or authors' websites.

\section{Real-time quantitative RT-PCR}

Real-time quantitative RT-PCR (qRT-PCR) was performed on total RNA from cell lines in accordance with standard Applied Biosystems protocols (Foster City, CA) and in accordance with our published methods [19]. All experiments were run in duplicates on an ABI 7700 sequence detector and data normalized to expression of beta-actin $(A C T B)$. Primers and probe for $M L L$ and GILZ qRT-PCR were purchased from Applied Biosystems (ABI Assays on Demand); the $M L L$ assay targeted exons 30-31 (Refseq NM_005933).

\section{RNAi knockdown of MLL expression}

Three pSM2 retroviral RNAi vectors for $M L L$ (V2HS_196843, V2HS_198375, V2HS_214961) and a non-silencing (NS) control vector were obtained from Open Biosystems (Huntsville, USA). For optimal mammalian expression, shRNA inserts were subcloned with EcoRI and XhoI into MSCV-LMP (MSCV/LTRmiR30PIG $\Delta$ RI, a generous gift from Prof. Scott Lowe, Cold Spring Harbour Laboratory [20]), which contains GFP and puromycin selection cassettes and drives miR30shRNA expression using the retroviral 5'LTR. V2HS_198375 (MLL198) was found to suppress $M L L$ expression most efficiently in transient transfection experiments and was used for subsequent experiments. The retroviral packaging cell line PA317 (selected in HAT medium) was transfected with linearised miR30shRNA plasmid DNA (for both NS control and MLL198) using Lipofectamine, and GFP-positive cells were selected with puromycin. Stably transfected retroviral-producing PA317 cell lines were $\gamma$-irradiated (30 Gy) and incubated at $37^{\circ} \mathrm{C}$ overnight before co-culture with PER-117 cells for 48 hours. Retrovirally infected PER-117 cells were subsequently removed and selected with puromycin to generate cell lines stably expressing shRNA for MLL (MLL-KD) or the NS control (MLLScr). Efficiency of RNAi knockdown for $M L L$ was assessed both by qRT-PCR as described above, and by immunoblot of nuclear protein extracted from cell lines in log-phase growth using standard methods. Antibodies used were mouse anti-MLL ${ }^{\mathrm{C}} / \mathrm{HRX}$, clone 9-12 (Upstate Cell Signaling Solutions, Temecula, CA), which detects the C-terminal proteolytic fragment of MLL $(\sim 180 \mathrm{kDa})$, and mouse anti-human $\beta$-actin as loading control (Pan Actin Ab-5 (ACTN05) NeoMarkers, Fremont CA). Densitometric quantitation of protein bands from multiple extractions taken at independent time points and from different cell-line stocks was performed using ImageJ software http://rsbweb.nih.gov/ij/, with MLL expression normalized to $\beta$-actin loading. 


\section{Cellular assays}

Cell growth and viability were measured using the ViCELL XR Viable Cell Analyzer (Beckman Coulter). Cells in exponential growth phase were seeded at $5 \times 10^{5} \mathrm{ml}^{-1}$ in a 96-well plate in the presence or absence of dexamethasone $(10 \mu \mathrm{g} / \mathrm{ml}-258 \mu \mathrm{g} / \mathrm{ml}$, Mayne Pharma Pty Ltd, VIC, Australia), $0.025 \mu \mathrm{g} / \mathrm{ml}$ cytarabine (ARAC; Pharmacia Pty Ltd, NSW, Australia), $0.01 \mu \mathrm{g} / \mathrm{ml}$ methotrexate (MTX; David Bull Laboratories), or 1 Gy gammairradiation, and incubated for two days at $37^{\circ} \mathrm{C}$ before measuring cell survival. Each drug concentration or condition was tested in triplicate and data were normalised to values obtained from untreated cells. For metabolic assays, cells in exponential growth were seeded at $5 \times 10^{5}$ $\mathrm{ml}^{-1}$ in fresh media and incubated for two days at $37^{\circ} \mathrm{C}$ before harvesting supernatants. Glucose and lactate supernatant concentrations were measured using the Amplex Red kit (Invitrogen, Australia), substituting lactate oxidase (Sigma, Australia) as required. For assessment of GILZ induction, MLL-KD and MLL-Scr cells in exponential growth were incubated with $1 \mu \mathrm{M}$ dexamethasone (Mayne Pharma Pty Ltd, VIC, Australia) for four hours prior to RNA extraction and measurement by qRT-PCR.

\section{Results}

\section{MLL mRNA Expression and GC resistance in T-ALL Cell} Lines

Our laboratory has developed an authenticated panel of pediatric T-ALL cell lines that have been grown in the absence of drug selection. These cultures retain critical features of the primary disease and their drug resistance profile parallels the spectrum of resistance that has been observed in primary patient specimens [12]. We recently examined the baseline resistance of these $15 \mathrm{~T}$-ALL cell lines to the GCs DEX and MPRED [12] and correlated the data with gene expression profiles as determined by HG-U133A microarray [11]. Although these lines have been cultured without prior exposure to in vitro drug selection pressure they demonstrate a natural spectrum of GC resistance, with IC50 values across the panel varying by 4-5 orders of magnitude (Figure 1A). This resistance profile is not explained by mutations in the glucocorticoid receptor (GR) or variations in its level of expression [21], indicating that defects downstream of the GR are primarily responsible for GC resistant phenotypes in these cell lines.

Our analysis of the microarray data revealed that GC resistance was significantly correlated with reduced expression of $M L L$ [11]. To confirm this correlation we used qRT-PCR to measure $M L L$ mRNA expression across the panel, using a probe targeting the 3 ' end of the $M L L$ coding region. Expression levels measured by qRT-PCR were highly correlated with resistance to both
GCs (Figure 1A; correlation vs. dexamethasone IC50 -0.849 ( $\mathrm{p}<0.0001)$, methylprednisolone IC50 -0.851 (p $<0.0001)$ ). Whilst translocations of the $M L L$ gene are prevalent in infant ALL they are infrequent in T-ALL $[8,9,22]$, suggesting that the observed correlation reflected expression of the wild-type gene. Indeed, TALL cell line karyotypes indicated no abnormalities at the 11q23 MLL-locus [12], a conclusion confirmed by Southern Blot for all 15 cell lines (data not shown). On the HG-U133A microarray there are five independent probes for $M L L$, and these span the entire length of the gene, encompassing both sides of the major break region (MBR) that is involved in almost all translocation events (Figure 1B). Across the 15 T-ALL cell lines correlation of $M L L$ mRNA expression and $\mathrm{GC}$ resistance was significant for all five probe sets (median probe significance DEX $\mathrm{p}=0.0025$, MPRED $\mathrm{p}<0.0001$ ) indicating no discrepancy in expression between the 5' and 3' regions of the gene. Based on these data we conclude that the observed correlation with GC sensitivity in TALL cell lines is related to expression levels of wild-type $M L L$ rather than $M L L$-translocation products.

\section{Biological features of MLL expression in T-ALL}

To gain further insight into the transcriptional programs associated with $M L L$, the expression profile of this gene across the T-ALL cell line panel was correlated to the expression of all other genes on the microarray. This output was analyzed with GSEA to identify the biological networks associated with variations in $M L L$ expression. The strongest signatures were returned from the C2 (curated pathway) and C4 (computational gene network) databases, with 17 and 83 enriched gene sets respectively falling within the significant GSEA false discovery rate (FDR). Very few significantly enriched gene sets were identified from genomic loci and regulatorymotif databases ( $\mathrm{C} 1$ and $\mathrm{C} 3$ ). The top ranked significant gene sets from the $\mathrm{C} 2$ and $\mathrm{C} 4$ databases are listed in Tables $1 \& 2$. The majority of these pathways are involved with the control of cell growth and metabolism (e.g. $M Y C$-regulated pathways, RNA transcription, oxidative phosphorylation, the TCA cycle, proteasomal regulation, nucleotide synthesis, translation initiation and antioxidant defense). The overwhelming direction of expression of these pathways was a negative correlation with expression of $M L L$. Thus lower expression of $M L L$ in these cell lines is associated with signatures consistent with a proliferative phenotype. In addition the expression levels measured by each of the five $M L L$ probe sets were found to correlate significantly with cell line doubling times [12] (median correlation 0.67, $\mathrm{p}<0.01$ ). These findings are in keeping with our previous observation that reduced expression of $M L L$ is part of a proliferative metabolism signature that is associated with 
A

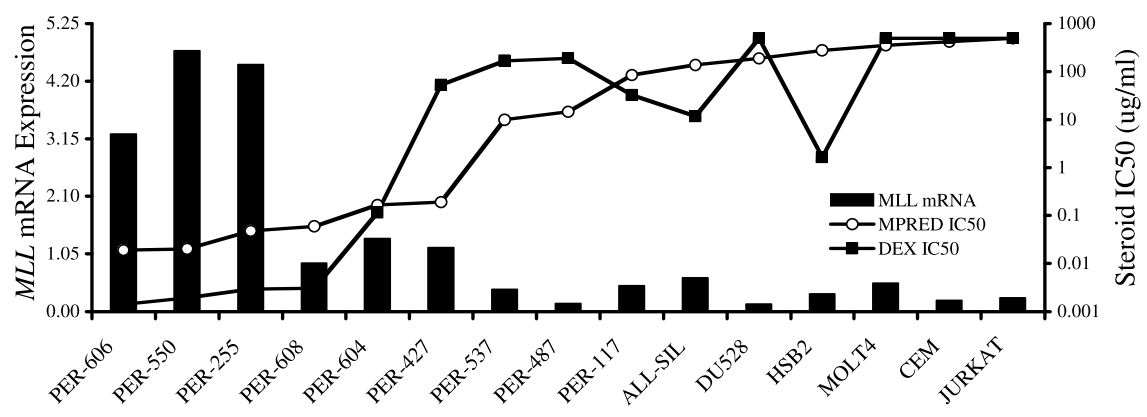

B

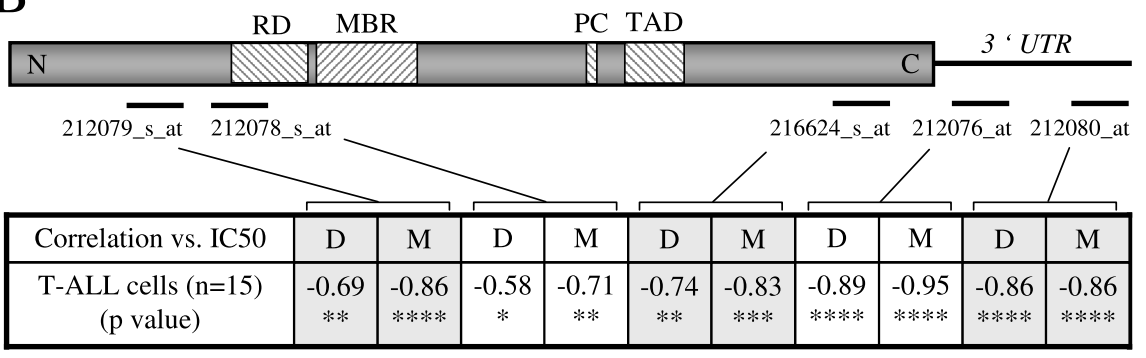

Figure 1 Relationship between MLL expression and GC resistance in T-ALL Cell Lines. (A) Normalized MLL mRNA expression across the TALL cell line panel as measured by qRT-PCR (bars) and IC50 values for MPRED (open circles) and DEX (closed squares); (B) Schematic of MLL mRNA indicating the target location of five microarray probes (indicated by solid lines) and protein domains within the coding region: MBR, Major Break Region; RD, Repression Domain; TAD, Transactivation Domain; PC, site of proteolytic cleavage. Correlation of expression level vs. cell line IC50 for DEX (D) and MPRED (M) is indicated for each probe $\left({ }^{*} p<0.05,{ }^{* *} p<0.01,{ }^{* * *} p<0.001,{ }^{* * *} p<0.0001\right.$ ).

Table 1 Top ranked GSEA gene sets from the C2 database (curated pathways) associated with MLL expression profiles in T-ALL cell lines

\begin{tabular}{lll}
\hline Gene Set & Description of Biological Pathway & FDR * \\
\hline Electron_transport_chain & Electron transport chain & 0.137 \\
\hline Glycolysis_gluconeogenesis & Glycolysis and gluconeogenesis & 0.142 \\
\hline Peng_leucine_down & Down-regulated in response to leucine starvation & 0.145 \\
\hline RNA_transcription_reactome & RNA transcription reactome & 0.145 \\
\hline Mitochondria & Mitochondrial genes & 0.148 \\
\hline Aminoacyl_tRNA_biosynthesis & Amino-acyl tRNA biosynthesis & 0.151 \\
\hline Human_mitodb_6_2002 & Mitochondrial genes & 0.152 \\
\hline Hdaci_colon_cur24hrs_up & Genes upregulated by curcumin, transcription inhibitor & 0.156 \\
\hline Hdaci_colon_cur48hrs_up & Genes upregulated by curcumin, transcription inhibitor & 0.163 \\
\hline Myc_huvec_sage_array_up & Genes up-regulated by myc & 0.176 \\
\hline Peng_rapamycin_down & Down-regulated in response to rapamycin & 0.183 \\
\hline Oxidative_phosphorylation & Oxidative phosphorylation & 0.190 \\
\hline tRNA_synthetases & tRNA synthetases & 0.192 \\
\hline Proteasome_pathway & Proteasomal pathway genes & 0.200 \\
\hline Peng_glutamine_down & Down-regulated in response to glutamine starvation & 0.203 \\
\hline Krebs_TCA_cycle & Krebs (TCA) cycle genes & 0.204 \\
\hline Proteasome & Proteasome genes & 0.238 \\
\hline
\end{tabular}

* FDR, false discovery rate; GSEA cutoff for significance FDR $<0.25$. 
Table 2 Top ranked GSEA gene sets from the C4 database (computed gene networks) associated with MLL expression profiles in T-ALL cell lines

\begin{tabular}{|c|c|c|}
\hline Gene Set & Description of Network Hub Genes and Associated Functions & FDR * \\
\hline MORF_PRDX3 & Peroxiredoxin 3 - MYC-mediated proliferation, glucose responses & 0.132 \\
\hline MORF_SOD1 & Superoxide dismutase 1 - mitochondria, oxidative metabolism & 0.135 \\
\hline MORF_MAP2K2 & MAP2K2 - ERK, JNK, p38, NFkB, and apoptosis pathways & 0.138 \\
\hline MORF_PTPN11 & Protein tyrosine phosphatase, cell growth, differentiation, metabolism & 0.140 \\
\hline GNF2_RAN & RAS oncogene family - cell cycle, mitotic spindle regulation & 0.143 \\
\hline MORF_GMPS & Guanine monphosphate synthetase - purine synthesis, cell cycle & 0.146 \\
\hline MORF_DEAF1 & DEAF1 or supressin, inhibitor of proliferation & 0.152 \\
\hline MORF_ERH & Enhancer of rudimentary homolog - cell cycle regulator & 0.155 \\
\hline GNF2_NS & Nucleostemin - cell cycle progression in stem cells, links with p53 & 0.158 \\
\hline MORF_GPX4 & Glutathione peroxidase 4 - cellular antioxidant defence & 0.159 \\
\hline MORF_AATF & Apoptosis antagonizing transcription factor & 0.160 \\
\hline MORF_EIF3S2 & EIF3S2 - eukaryotic translation initiation factor & 0.164 \\
\hline MORF_ATOX1 & ATX1 antioxidant protein 1 homolog - antioxidant defense & 0.165 \\
\hline MORF_El24 & Etoposide induced mRNA - early p53 response gene & 0.166 \\
\hline MORF_PSMC1 & Proteasome 265 subunit, ATPase & 0.173 \\
\hline MORF_RAN & RAS oncogene family - cell cycle, mitotic spindle regulation & 0.179 \\
\hline MORF_RAB5A & Ras-associated protein - exocytosis, actin organisation & 0.180 \\
\hline MORF_UNG & Uracil-DNA glycosylase - base-excision DNA repair pathway & 0.182 \\
\hline MORF_FBL & Fibrillarin - component of snRNP synthesis of ribosomal RNA & 0.203 \\
\hline GCM_MAX & Myc-associated factor $X$ - transcriptional regulator & 0.224 \\
\hline
\end{tabular}

* FDR, false discovery rate; GSEA cutoff for significance FDR $<0.25$.

GC resistance in T-ALL cell lines [11]. Importantly, several gene sets were involved with the regulation of apoptosis (MORF_AATF, MORF_MAPK2), p53 response (MORF_EI24, GNF2_NS) and DNA damage repair (MORF_UNG), with the direction of association linking reduced $M L L$-expression with the activation of antiapoptotic transcriptional networks (Table 2).

\section{MLL-Translocation Partner Genes Correlate with MLL Expression}

Recent evidence suggests that the genes most commonly translocated with $M L L$ are not selected at random but may in fact be functionally related as part of an ' $M L L$ web' $[5,23,24]$. If this is true, then in the context of the observed relationship between $M L L$ expression and GC resistance in the present study (Figure 1A) one might predict that the expression of these genes would similarly be correlated with GC resistance in our T-ALL cell lines. Of the $>50$ known translocation partner genes of $M L L, 43$ are represented on the HG-U133A microarray (corresponding to a total of 93 probe sets). Despite the absence of $M L L$-translocations in the T-ALL cell lines we observed that a large number of these (18 genes, 26 probe sets) were significantly correlated to MPRED and DEX resistance (Table 3 ). This association is much greater than would be predicted by chance alone (exact binomial test, $\mathrm{p}<0.001)$. It is relevant that the majority of the genes listed in Table 3 are involved in transcriptional regulation (GMPS, DCPS, ELL, LPP, AF10, $C R E B B P, E P 300, A F 4)$, proliferation (GAS7) or metabolism $(C B L, G P H N$ and $A C A C A$, the latter being the rate limiting enzyme for conversion of acetyl-coA into cholesterol). The correlation of these genes with GC resistance may therefore be reflective of the metabolic and proliferative changes driving this phenotype in T-ALL cell lines of which $M L L$ appears to be a part [11].

\section{Reduced MLL Expression in T-ALL Patients is Associated with GC Resistance and Relapse}

Since our data indicated an association between GC sensitivity and expression levels of $M L L$ in T-ALL in vitro we looked for further evidence in the literature for such an association. Holleman et al previously examined the ex vivo sensitivity of diagnostic pediatric ALL patient specimens to individual induction therapy agents and correlated the findings with gene expression data measured in the same samples using HG-U133A Affymetrix microarrays [17]. We examined this data for the expression level of $M L L$ in T-ALL patient specimens from this cohort that were determined to be sensitive or resistant to prednisolone. Importantly, three of the five $M L L$ probe sets on the array showed a significantly lower 
Table 3 MLL Translocation Partner Genes Significantly Correlated with GC IC50 in T-ALL Cell Lines

\begin{tabular}{|c|c|c|c|c|c|}
\hline Probe Set & Gene Title & Symbol & Chr & MPRED & DEX* \\
\hline 220773_s_at & Gephyrin & GPHN & $14 q 23.3$ & 0.915 & 0.670 \\
\hline 212186_at & Acetyl-CoA carboxylase alpha & $A C A C A$ & $17 q 21$ & 0.767 & 0.558 \\
\hline 214431_at & Guanine monphosphate synthetase & GMPS & $3 q 24$ & 0.754 & 0.505 \\
\hline 218774_at & Decapping enzyme, scavenger & DCPS & $11 \mathrm{q} 24.2$ & 0.637 & 0.744 \\
\hline 204096_s_at & Elongation factor RNA pol ॥ & ELL & 19p13.1 & 0.581 & 0.779 \\
\hline 202821_s_at & LIM domain containing preferred translocation partner in lipoma & $\angle P P$ & $3 q 28$ & 0.577 & 0.418 \\
\hline 214358_at & Acetyl-CoA carboxylase alpha & ACACA & $17 q 21$ & 0.569 & 0.197 \\
\hline 216506_x_at & MLL (trithorax homolog, Drosophila); translocated to, 10 & MLLT10/AF10 & 10p12 & 0.560 & 0.293 \\
\hline 200713_s_at & Microtubule-associated protein, RP/EB family, member 1 & MAPRE1 & $20 q 11.1-11.23$ & 0.560 & 0.542 \\
\hline 211808_s_at & CREB binding protein (Rubinstein-Taybi syndrome) & CREBBP & $16 \mathrm{p} 13.3$ & 0.558 & 0.470 \\
\hline 215578_at & Gephyrin & GPHN & $14 q 23.3$ & 0.526 & 0.473 \\
\hline 209768_s_at & SEPT5 & SEPT5/PNUTL & $22 q 11.21$ & 0.519 & 0.229 \\
\hline 216503_s_at & MLL (trithorax homolog, Drosophila); translocated to, 10 & MLLT10/AF10 & 10p12 & 0.516 & 0.307 \\
\hline 211067_s_at & Growth arrest-specific 7 & GAS7 & $17 p 13.1$ & -0.300 & -0.541 \\
\hline 210872_x_at & Growth arrest-specific 7 & GAS7 & 17p13.1 & -0.334 & -0.580 \\
\hline 202191_s_at & Growth arrest-specific 7 & GAS7 & $17 p 13.1$ & -0.385 & -0.624 \\
\hline 202192_s_at & Growth arrest-specific 7 & GAS7 & $17 p 13.1$ & -0.417 & -0.589 \\
\hline 202221_s_at & E1A binding protein p300 & EP300 & $22 q 13.2$ & -0.542 & -0.315 \\
\hline 212288_at & Formin binding protein 1 & FNBP1 & $9 q 34$ & -0.575 & -0.624 \\
\hline 209027_s_at & Abl-interactor 1 & $A B / 1$ & 10p11.2 & -0.580 & -0.417 \\
\hline 205068_s_at & Rho GTPase activating protein 26 & ARHGAP26 & $5 q 31$ & -0.607 & -0.661 \\
\hline 209028_s_at & Abl-interactor 1 & $A B / 1$ & 10p11.2 & -0.608 & -0.472 \\
\hline 214298_x_at & Septin 6 & SEPT6 & $\mathrm{Xq} 24$ & -0.615 & -0.386 \\
\hline 201924_at & MLLT2 & MLLT2/AF4 & $4 q 21$ & -0.660 & -0.671 \\
\hline 206607_at & Cas-Br-M (murine) ecotropic retroviral transforming sequence & $C B L$ & $11 \mathrm{q} 23.3$ & -0.681 & -0.456 \\
\hline 213579_s_at & E1A binding protein p300 & EP300 & $22 q 13.2$ & -0.742 & -0.404 \\
\hline
\end{tabular}

* Correlation coefficient ( $r$ ) of probe set expression with MPRED or DEX IC50 values; Chr, chromosomal locus; bold values, $p<0.05$. Genes are grouped together by positive (top) or negative correlation (bottom).

expression of $M L L$ in resistant samples confirming the association we observed in T-ALL cell lines. Figure 2A shows the data for the probe set with the strongest association (212079_s_at, $\mathrm{p}<0.001$ unpaired t-test), and for the summary of the five probe sets calculated using median expression values ( $\mathrm{p}<0.05$, unpaired $\mathrm{t}$-test). For further evidence of a link between $M L L$ expression and GC resistance we examined a dataset we have previously published comparing gene expression patterns in pediatric ALL specimens taken at the time of diagnosis and relapse [14]. Although we were not able to directly measure the GC sensitivity of these specimens it is known that almost all patients initially respond to induction therapy and achieve first remission, whilst GC resistance is a well-documented feature of relapse $[25,26]$. It is therefore reasonable to expect that many of the relapse specimens in this cohort would have elevated GC resistance compared to their diagnostic counterparts. Examining the same $M L L$ probe sets as above, we observed a decrease in $M L L$ expression in T-ALL relapse specimens vs. diagnosis specimens (Figure 2B) comparable to that measurable in GC resistant vs. sensitive specimens [17]
(Figure 2A). This differential was only statistically significant for probe set 212079_s_at ( $<0.001$, unpaired $\mathrm{t}$-test), but the same trend was visible for the other four probe sets and is reflected in the summary of the median expression values for all five probes (Figure 2B). Since both of these studies involve T-ALL patients it is likely that the majority of patients within these cohorts do not have rearrangements affecting $M L L$. Taken together, this data provides clear support from two independent data sets that the correlation we have observed between wild-type $M L L$ expression and GC sensitivity in T-ALL in vitro appears to also be relevant in vivo.

\section{Relevance of MLL Expression Level in Patients with MLL- Disease}

In our T-ALL cell lines we observed a 35 -fold variation in $M L L$ expression across the panel that correlated with GC resistance (Figure 1A). To assess the degree with which endogenous $M L L$ expression levels vary in primary ALL patient specimens we analyzed data published by Ross et al who performed gene expression profiling of pediatric ALL subtypes [18]. Figure 3A shows that of 

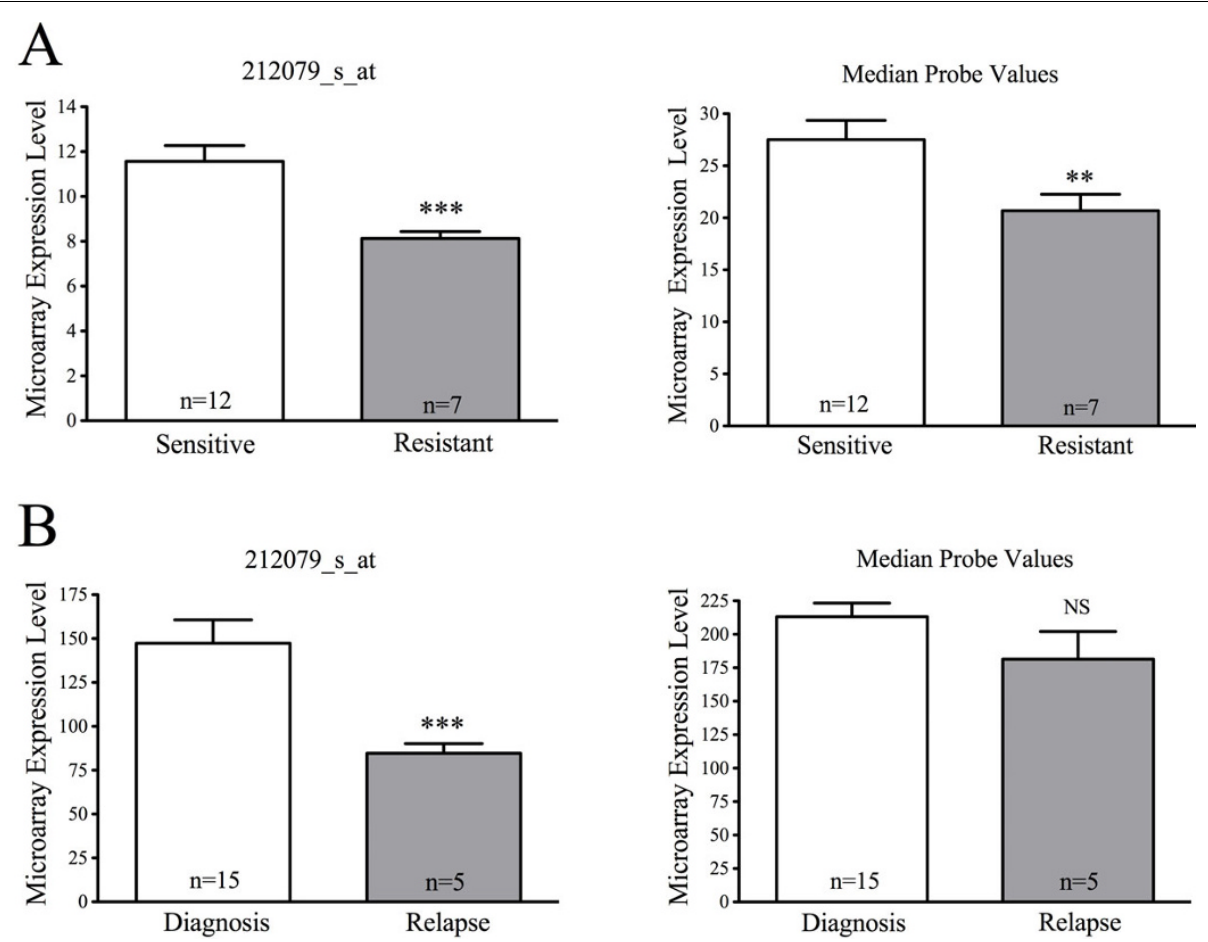

Figure 2 Reduced MLL expression is associated with GC resistance and relapse in T-ALL patients. Published HG-U133A microarray datasets were examined for the expression of MLL using either a single probe (212079_s_at) or the median of all five MLL probe sets on the array. Data represent the mean \pm SEM (linear scale) of the indicated patient numbers (n). (A) Difference in MLL expression in pediatric T-ALL patient specimens with ex vivo sensitivity or resistance to prednisolone [17]; (B) Difference in MLL expression in pediatric T-ALL patient specimens measured at diagnosis or relapse [14].

all the pediatric ALL subtypes, the widest variations in $M L L$ expression levels are found in patients with T-lineage ALL and those with $M L L$-rearrangements. To examine the prognostic relevance of $M L L$ expression variation in patients with $M L L$-disease we examined a publication describing the use of Affymetrix HG-U95v2 microarrays to examine gene expression patterns in ALL patients with $M L L$-rearrangements [16]. These authors reported that such patients could be clustered on the basis of their genome-wide transcriptional profile into two distinct subgroups (called A and B) that demonstrated dramatically different survival rates (Figure 3B, box, $p=0.0005$ ). By analyzing the data from their study we have ascertained that the expression of $M L L$ was significantly lower in poor-outcome patients (Group A) compared to those with good outcome (Figure 3B, bar chart, $\mathrm{p}=0.008)$. The HG-U95v2 probe for $M L L$ targets the 3' UTR of the gene, meaning that it would either detect expression of the full-length (non-translocated) $M L L$ allele remaining in these patients, or the expression of any reciprocal fusion that was transcribed as far as this 3 ' probe. Certainly it would not detect signal from primary $M L L$-translocation products. While the authors did not experimentally determine GC sensitivity in their study [16], the data are consistent with the hypothesis that the level of wild-type $M L L$ expression is linked to therapeutic outcome even in patients that have an $M L L$-translocation on the alternate allele.

\section{MLL Knockdown Increases Resistance to GC Exposure and DNA Damage}

To assess the role of wild-type $M L L$ in GC resistance phenotypes we used a retroviral RNAi expression system in the PER-117 T-ALL cell line to generate cell lines stably expressing shRNA for MLL (MLL-KD) or a non-silencing shRNA scrambled control (MLL-Scr). MLL mRNA expression in MLL-KD cells was $69 \%$ lower on average than in MLL-Scr control cells as assessed by qRT-PCR (Figure $4 \mathrm{~A}, \mathrm{p}<0.0001$ ). This correlated to a $\sim 20 \%$ reduction in MLL nuclear protein as assessed by immunoblot (Figures $4 \mathrm{~B}$ and $4 \mathrm{C}, \mathrm{p}<0.05$ ). Proliferation assays demonstrated that MLL-KD cells grew approximately $10 \%$ faster on average than MLL-Scr cells (Figure 4D, p $<0.05$ ANOVA). To assess GC sensitivity in the two lines, cell viability was assessed after a two-day incubation with dexamethasone (Figure 4E). MLL-KD demonstrated increased viability compared to MLL-Scr cells at all doses tested ( $\mathrm{p}<$ 0.05 , two-way ANOVA) indicating GC resistance. To assess the specificity of this protective effect we examined the sensitivity of the cells to gamma-irradiation, and 


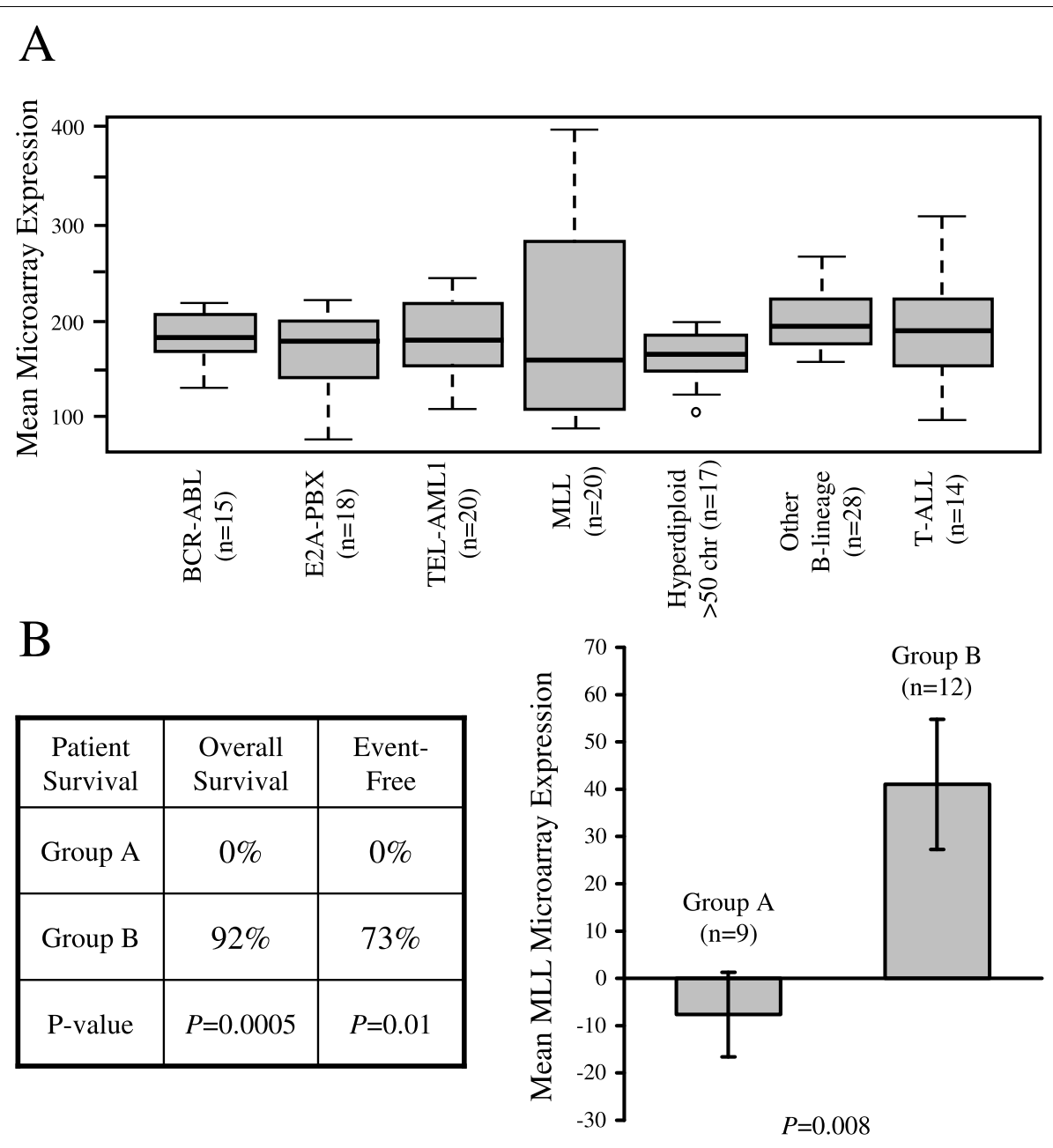

Figure 3 MLL expression patterns in patients with $M L L$-disease. (A) Box and whisker plot of published microarray data [18] showing the variation of MLL expression in different ALL subgroups (HG-U133Plus2 probe 212076_at); (B) Analysis of published microarray data from ALL patients with MLL-rearrangements [16]. This study described two clusters of patients (A and B) with significantly different survival rates (boxed data) and expression of MLL (graph, mean \pm SEM).

incubation with cytarabine (ARAC) and methotrexate (MTX). Interestingly, MLL-KD cells showed greater survival following gamma-irradiation indicating resistance to DNA damage (Figure 5A, $\mathrm{p}<0.05$ unpaired $\mathrm{t}$-test). Resistance to ARAC and MTX however was not significantly different between the two cell lines. The proportion of dying (necrotic) cells after two days was significantly reduced in MLL-KD cells in response to both dexamethasone and gamma-irradiation, indicating a cytoprotective effect of $M L L$ knockdown (Figure 5B). Baseline viability in untreated cells was not significantly different between the cell lines.

To assess the effects of $M L L$ knockdown on cell metabolism we compared rates of glucose consumption and lactate production between the two cell lines. Consistent with an increased rate of proliferation MLL-KD cells demonstrated an increased rate of glucose consumption compared to control cells. This was accompanied by a decreased rate of lactate production, resulting in a significant drop in the lactate production:glucose consumption ratio in MLL-KD cells (Figure 5C). Finally, since $M L L$ is known to be a master transcriptional regulator we assessed whether the GC resistant phenotype of MLL-KD cells might represent transcriptional suppression of GC response elements by measuring the induction of GILZ, a well-characterized GC-response gene, following incubation with dexamethasone. There was no significant difference in the induction of GILZ mRNA between MLL-KD and MLL-Scr cell lines following a 4 hour incubation with dexamethasone (Figure 5D), indicating that GC-transcriptional responses in MLL-KD cells appeared to be intact. 

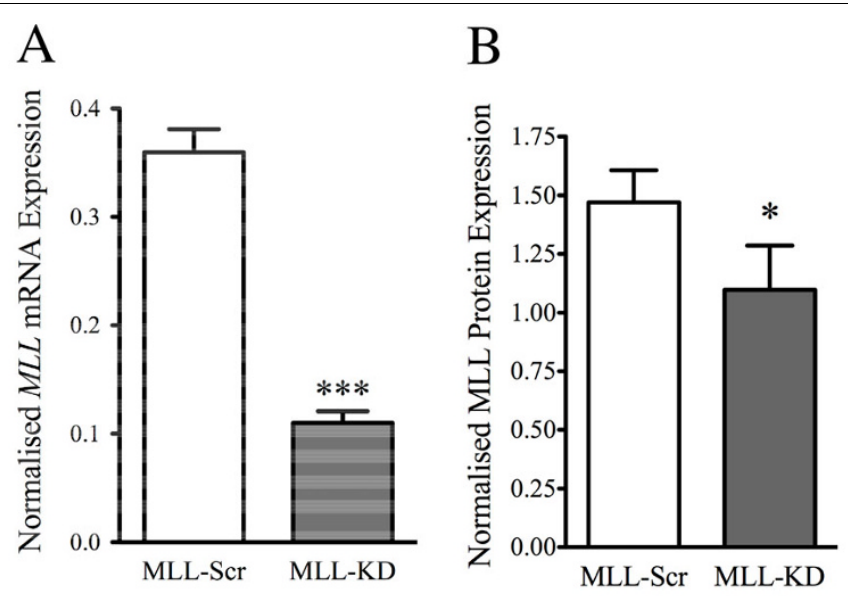

\section{$\mathrm{C}$}
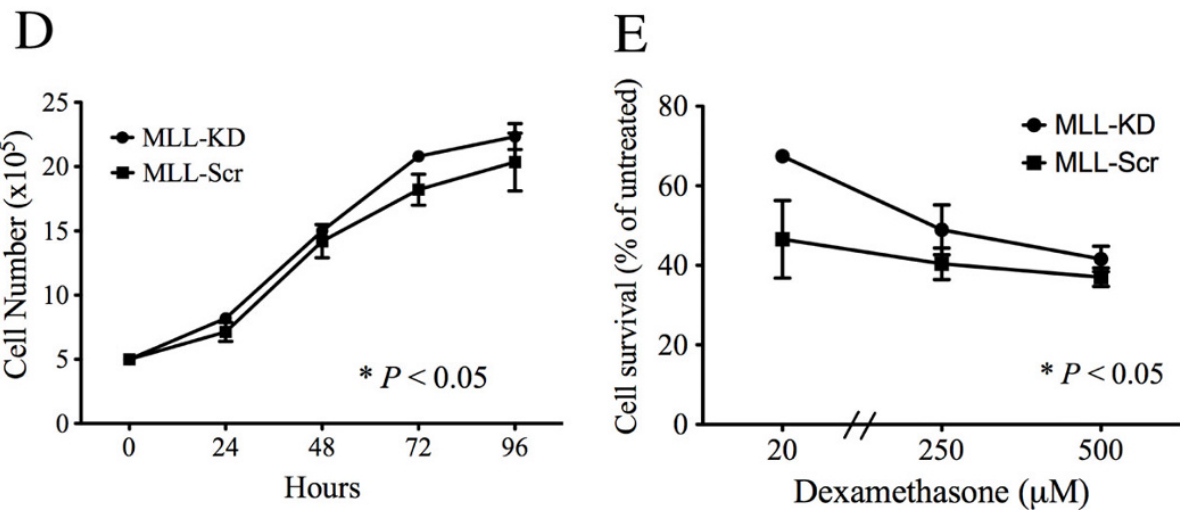

Figure 4 Effect of $M L L$ knockdown on proliferation and sensitivity to dexamethasone. (A) Level of stable MLL mRNA knockdown in MLLKD cells as measured by qRT-PCR compared to MLL-Scr cells expressing non-silencing scrambled shRNA; (B) Reduction of MLL nuclear protein expression in MLL-KD cells as assessed by immunoblot detection of the $\mathrm{MLL}^{\mathrm{C}}$ proteolytic fragment from four independent extractions and normalized to $\beta$-actin loading control; (C) Representative immunoblot of nuclear MLL ${ }^{\mathcal{C}}(\sim 180 \mathrm{kD}$, top panel) and $\beta$-actin ( $42 \mathrm{kD}$, bottom panel) protein expression in MLL-Scr and MLL-KD cell lines; (D) Proliferation of MLL-Scr and MLL-KD cell lines over four days; (E) Differential growth of MLL-Scr and MLL-KD cells over two days in the presence of dexamethasone; In each case (A-B, D-E) data represent mean \pm SEM from 3-6 independent experiments; Statistical analysis was by t-test $(A, B)$ or ANOVA $(D, E) ;{ }^{*} p<0.05,{ }^{* * *} p<0.001$.

\section{Discussion}

Although there are conflicting reports of the effect of $M L L$-rearrangements on steroid resistance $[7,8]$, it is clear that all infants with $M L L$-rearrangements have significantly worse prognosis than those with non-rearranged $M L L$ regardless of the type of translocation involved $[3,27]$. However, the present study has been conducted using T-ALL cell lines without $M L L$-translocations and provides evidence that in the absence of such translocations cellular GC sensitivity is related to the level of expression of wild-type $M L L$. One interpretation of this data is that alterations in $M L L$ support the proliferative phenotype that we have previously associated with GC resistance [11]. In lymphocytes, GCs are thought to trigger a metabolic crisis that ultimately leads to apoptosis [28]. In addition to suppressing apoptotic potential through the modulation of mitochondrial energetics, up-regulation of biosynthetic and metabolic pathways to support proliferation may therefore confer $\mathrm{GC}$ resistance by offsetting the adverse metabolic consequences of GC signalling [11]. $M L L$ has recently been shown to be important for the control of cell proliferation but the mechanism is complex, involving a bimodal pattern of expression throughout the cell cycle [29]. In our experiments, suppression of $M L L$ was associated with a small increase in proliferation and glucose consumption but decreased lactate production, indicating a shift away from aerobic glycolysis to alternative pathways, such as oxidative phosphorylation or the pentose-phosphate shunt. Besides energy production, these pathways are essential for the synthesis of macromolecules, nucleotides and nucleic acids required for proliferation [30].

In addition to elevated GC resistance, knockdown of $M L L$ expression was associated with increased resistance to gamma-irradiation indicating an unexpected protection from the effects of DNA-damage. Recently it has 

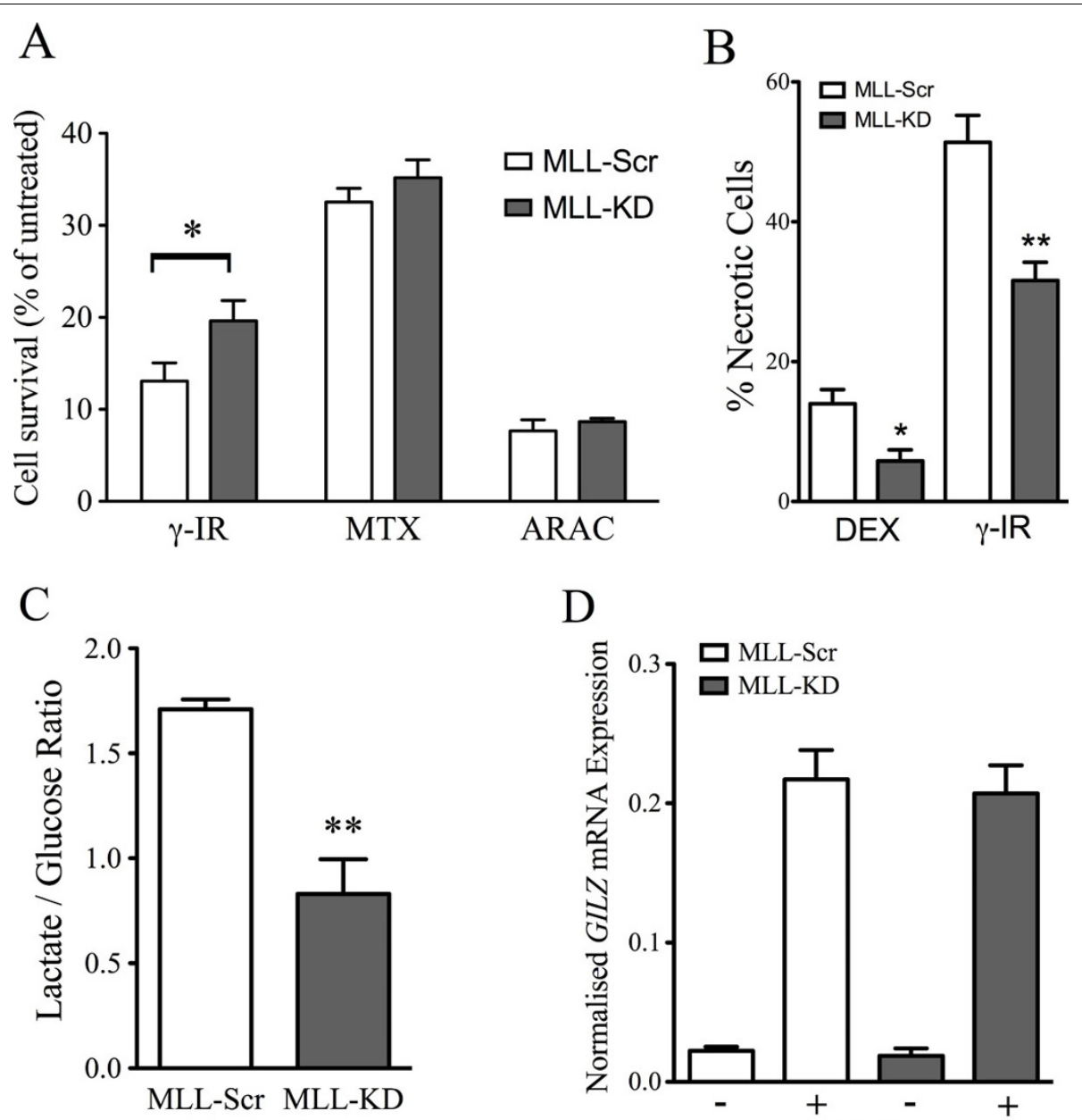

$\mathrm{D}$

Figure 5 Effect of $\boldsymbol{M L L}$ knockdown on cellular resistance, metabolism and GC signaling. (A) Effect of gamma-irradiation ( $\gamma-I R, 1$ Gy) methotrexate (MTX, $0.01 \mu \mathrm{g} / \mathrm{ml}$ ), cytarabine (ARAC, $0.025 \mu \mathrm{g} / \mathrm{ml}$ ) on growth of MLL-Scr and MLL-KD cell lines over two days; (B) Percentage of dying or necrotic cells (normalized to untreated) in MLL-Scr and MLL-KD after 48 hours in the presence of dexamethasone (DEX, $250 \mu M$ or 500 $\mu \mathrm{M})$ or following gamma-irradiation $(\gamma-\mathrm{IR}, 1 \mathrm{~Gy})$; (C) Ratio of lactate production/glucose consumption over two days in MLL-Scr and MLL-KD cells; (D) Relative expression of GILZ mRNA as measured by qRT-PCR in MLL-Scr and MLL-KD cell lines incubated for four hours in the absence (-) or presence $(+)$ of dexamethasone $(1 \mu \mathrm{M})$; In each case (A-D) data represent mean \pm SEM from 3-6 independent experiments with statistical analysis by unpaired t-test; ${ }^{*} p<0.05,{ }^{* *} p<0.01$.

been demonstrated that the $M L L$ family of H3K4 methyltransferases are critical components of an E2F1signalling pathway that mediates links cell cycle control to DNA damage responses, and that their knockdown attenuates the apoptotic response to adriamycin [31]. This highlights the tumor suppressor role of these proteins and is consistent with the protection from DNAdamage we have observed following $M L L$-knockdown in T-ALL cell lines. In contrast however, no protective effect of $M L L$-knockdown was seen for ARAC or MTX in the present study. Whilst one might expect that suppression of DNA-damage response pathways should increase resistance to both of these agents, it is interesting to note that, unlike GCs, elevated resistance to neither of these drugs is associated with $M L L$ - rearrangement $[32,33]$; infants in fact are known to be generally more sensitive to ARAC $[8,32]$. There may therefore be some unexplained insult specificity in the role of $M L L$ in mediating responses to DNA-damage.

Across the T-ALL cell lines there was a 35 -fold variation in the level of $M L L$-expression. Surprisingly the mechanisms controlling expression of wild-type $M L L$ have not been extensively studied, with most work focusing on the downstream effects of the gene and its various fusion products. However the putative $M L L$ promoter has binding motifs for a large number of transcription factors, including SREBF1 (sterol regulatory element binding transcription factor) and MYC. MYC is a pivotal player in the control of cell cycle and apoptosis [34], is one of the known downstream targets of GC 
signaling in lymphocytes [35], and has been reported to be up-regulated in $M L L$-disease [36]. $M L L$ expression is also likely to be subject to miRNA control, with numerous miRNA binding sites predicted to reside in the $M L L$ 3'UTR. Although downstream effects of $M L L$ or $M L L-$ translocations on miRNA expression has been reported by a number of groups, to our knowledge only one recent study has reported the upstream miRNA regulation of $M L L$ itself [37]. In that study ectopic expression of mirR-221 and miR128 was shown to affect levels of $M L L, M L L$-fusions and GC sensitivity in ALL cell lines [37], consistent with the hypothesis that levels of $M L L$ expression are important for GC resistance. It remains to be seen whether the observed effects of miRNA ectopic expression on GC sensitivity were due to effects on $M L L$-fusion proteins or endogenous wild-type $M L L$ and the hierarchy for these mechanisms therefore remains to be untangled.

How do the present findings, performed in T-ALL with no $M L L$-translocations, relate to patients with $M L L$-disease? Although loss-of heterozygosity (LOH) at the $M L L$ locus has been reported to be a relatively frequent event in childhood ALL, consistent with a potential role as a tumor suppressor [38], this is not the case in patients with $M L L$-disease where one wild-type copy of $M L L$ appears to be retained [38-40]. This indicates that allele loss and $M L L$-translocation are mutually exclusive oncogenic events, but little focus has been given to the regulation of the remaining wild-type allele following translocation. However Whitman et al have recently demonstrated that in myeloid leukemia $M L L$ partial tandem duplications (PTD) are associated with silencing of the wild-type $M L L$ copy through an autoregulatory mechanism involving altered methylation [41]. Interestingly, in one MLL-PTD patient wild-type $M L L$ was expressed at diagnosis but absent at relapse, suggesting a correlation with disease progression. Wild-type $M L L$ expression could be re-induced in primary blasts with the use of DNA methyltransferase (DNMT) or histone deacetylase (HDAC) inhibitors, or suppression of the MLL-PTD transcript, and was associated with increased apoptotic sensitivity and reduced colonyforming capability. Other workers have recently demonstrated down-regulation of wild-type $M L L$ in myeloid leukemia patients with different types of rearranged$M L L$ [42] suggesting that it may be a common feature of $M L L$-related leukemia.

\section{Conclusions}

Based on the evidence presented we hypothesize that GC resistance in patients with $M L L$-disease may partly result from decreased expression and tumor suppressive effects of wild-type $M L L$, either through a gene-dosage effect following the functional loss of one allele via translocation, auto-regulation from the $M L L$-fusion protein, or altered miRNA/transcription factor signaling. This would help to explain why GC-resistance is a common feature of most patients with $M L L$-disease despite the wide variety of possible gene rearrangements. Amplifications of the $M L L$ gene do occur but are much more rare. To our knowledge only one report exists where such a patient has been tested for ex vivo GC sensitivity [43] - in that small study a single patient with $M L L$ amplification demonstrated GC sensitivity whilst all patients with $M L L$ deletions or rearrangements demonstrated GC resistance, observations entirely consistent with our hypothesis.

We do not propose that the $M L L$-translocation event itself is without oncogenic effects since this has been clearly demonstrated by other workers, but rather that our data may help to explain the poor-response to therapy in this disease. Neither do our findings negate the possibility that $M L L$-fusion proteins themselves may have additional effects upon apoptotic sensitivity. Indeed, recent experiments have shown that multiple $M L L$-fusion proteins inhibit $\mathrm{p} 53$ and confer resistance to DNA damage [44]. However, it is important to note that in these experiments fusion protein constructs were ectopically expressed into cell lines containing wild-type $M L L$. In view of the evidence discussed here it would be important to know whether expression of endogenous $M L L$ was altered during these experiments and whether this contributed to the observed anti-apoptotic effects. Increased resistance to DNA damage-induced apoptosis has been proposed as a phenotype of $M L L$-disease that explains the short latency associated with disease emergence [45]. It is possible that this effect could originate from the loss of tumor suppressor function of the wildtype $M L L$ as well as from direct anti-apoptotic effects of the fusion protein.

During the preparation of this manuscript Liu et al [46] published a report describing a role for wild-type MLL in the maintenance of genome integrity through the regulation of the $\mathrm{S}$-phase cell cycle checkpoint. DNA synthesis in cells deficient in wild-type MLL was found to be resistant to ionizing radiation and a range of DNA-damaging agents, supporting a role for wildtype MLL in the mediation of cellular DNA damage responses [46]. Under this model, MLL-fusion proteins acted as dominant negative mutants to abrogate the ATR-mediated stabilization of wild-type MLL reported to occur in response to DNA damage. The findings are in keeping with those from the present study and support our conclusion that reduced levels of wild-type MLL can contribute to increased cellular resistance even in the absence of an MLL-translocation event. 


\section{Conflicts of interests}

The authors declare that they have no competing interests.

\section{Authors' contributions}

AHB directed research, analyzed data, prepared manuscript; JLR, MLP, JYSH, ALS, JF performed research, collected and analyzed data; MJF performed bioinformatics and statistical analysis; URK designed study, directed research, revised manuscript. All authors read and approved the final manuscript.

\section{Acknowledgements}

The authors would like to thank Prof Michael Garlepp (Curtin University of Technology School of Pharmacy) and the patients and parents with whom this study is connected. This research was funded by the Children's Leukaemia and Cancer Research Foundation, and the Cancer Council of Western Australia.

\section{Author details}

'Division of Children's Leukaemia and Cancer Research, Telethon Institute for Child Health Research, University of Western Australia Centre for Child Health Research, Perth, Australia. ${ }^{2}$ Division of Biostatistics and Genetic Epidemiology, Telethon Institute for Child Health Research, University of Western Australia Centre for Child Health Research, Perth, Australia. ${ }^{3}$ Curtin University of Technology School of Pharmacy, Perth, Western Australia.

Received: 11 January 2010 Accepted: 28 October 2010

Published: 28 October 2010

\section{References}

1. Pieters R, den Boer ML, Durian M, Janka G, Schmiegelow K, Kaspers GJ, van Wering ER, Veerman AJ: Relation between age, immunophenotype and in vitro drug resistance in 395 children with acute lymphoblastic leukemia-implications for treatment of infants. Leukemia 1998, 12:1344-1348.

2. Stam RW, den Boer ML, Pieters R: Towards targeted therapy for infant acute lymphoblastic leukaemia. Br J Haematol 2006, 132:539-551.

3. Hilden JM, Dinndorf PA, Meerbaum SO, Sather H, Villaluna D, Heerema NA, McGlennen R, Smith FO, Woods WG, Salzer WL, et al: CCG 1953: acute lymphoblastic leukemia in infants: analysis of prognostic factors. A report from the Children's Oncology Group. Blood 2006, 108:441-451.

4. Daser A, Rabbitts TH: The versatile mixed lineage leukaemia gene MLL and its many associations in leukaemogenesis. Semin Cancer Biol 2005, 15:175-188.

5. Meyer C, Schneider B, Jakob S, Strehl S, Attarbaschi A, Schnittger S, Schoch C, Jansen MW, van Dongen JJ, den Boer ML, et al: The MLL recombinome of acute leukemias. Leukemia 2006, 20:777-784.

6. Henderson MJ, Choi S, Beesley AH, Baker DL, Wright D, Papa RA, Murch A, Campbell $L$, Lock RB, Norris MD, et al: A xenograft model of infant leukaemia reveals a complex MLL translocation. Br J Haematol 2008, 140:716-719.

7. Palle J, Frost BM, Forestier E, Gustafsson G, Nygren P, Hellebostad M, Jonsson OG, Kanerva J, Schmiegelow K, Larsson R, Lonnerholm G: Cellular drug sensitivity in MLL-rearranged childhood acute leukaemia is correlated to partner genes and cell lineage. Br J Haematol 2005, 129:189-198.

8. Ramakers-van Woerden NL, Beverloo HB, Veerman AJ, Camitta BM, Loonen AH, van Wering ER, Slater RM, Harbott J, den Boer ML, Ludwig WD, et al: In vitro drug-resistance profile in infant acute lymphoblastic leukemia in relation to age, MLL rearrangements and immunophenotype. Leukemia 2004, 18:521-529.

9. Pui CH, Chessells JM, Camitta B, Baruchel A, Biondi A, Boyett JM, Carroll A, Eden $O B$, Evans WE, Gadner $H$, et al: Clinical heterogeneity in childhood acute lymphoblastic leukemia with $11 \mathrm{q} 23$ rearrangements. Leukemia 2003, 17:700-706.

10. Ploner $C$, Rainer J, Lobenwein $S$, Geley $S$, Kofler R: Repression of the BH3only molecule PMAIP1/Noxa impairs glucocorticoid sensitivity of acute lymphoblastic leukemia cells. Apoptosis 2009.

11. Beesley AH, Firth MJ, Ford J, Weller RE, Freitas JR, Perera KU, Kees UR: Glucocorticoid resistance in T-lineage acute lymphoblastic leukaemia is associated with a proliferative metabolism. Br J Cancer 2009, 100:1926-1936.
12. Beesley AH, Palmer ML, Ford J, Weller RE, Cummings AJ, Freitas JR, Firth MJ, Perera KU, de Klerk N, Kees UR: Authenticity and drug resistance in a panel of acute lymphoblastic cell lines. Br J Cancer 2006, 95:1537-1544.

13. Beesley AH, Palmer ML, Ford J, Weller RE, Cummings AJ, Freitas JR, Firth MJ, Perera KU, de Klerk NH, Kees UR: In vitro cytotoxicity of nelarabine, clofarabine and flavopiridol in paediatric acute lymphoblastic leukaemia. Br J Haematol 2007, 137:109-116.

14. Beesley AH, Cummings AJ, Freitas JR, Hoffmann K, Firth MJ, Ford J, de Klerk NH, Kees UR: The gene expression signature of relapse in paediatric acute lymphoblastic leukaemia: implications for mechanisms of therapy failure. Br J Haematol 2005, 131:447-456.

15. Subramanian A, Tamayo P, Mootha VK, Mukherjee S, Ebert BL, Gillette MA, Paulovich A, Pomeroy SL, Golub TR, Lander ES, Mesirov JP: Gene set enrichment analysis: a knowledge-based approach for interpreting genome-wide expression profiles. Proc Natl Acad Sci USA 2005, 102:15545-15550.

16. Tsutsumi S, Taketani T, Nishimura K, Ge X, Taki T, Sugita K, Ishii E, Hanada R, Ohki M, Aburatani H, Hayashi Y: Two distinct gene expression signatures in pediatric acute lymphoblastic leukemia with MLL rearrangements. Cancer Res 2003, 63:4882-4887.

17. Holleman A, Cheok MH, den Boer ML, Yang W, Veerman AJ, Kazemier KM, Pei D, Cheng C, Pui CH, Relling MV, et al: Gene-expression patterns in drug-resistant acute lymphoblastic leukemia cells and response to treatment. N Engl J Med 2004, 351:533-542.

18. Ross ME, Zhou X, Song G, Shurtleff SA, Girtman K, Williams WK, Liu HC, Mahfouz R, Raimondi SC, Lenny N, et al: Classification of pediatric acute lymphoblastic leukemia by gene expression profiling. Blood 2003, 102:2951-2959.

19. Dallas PB, Gottardo NG, Firth MJ, Beesley AH, Hoffmann K, Terry PA, Freitas JR, Boag JM, Cummings AJ, Kees UR: Gene expression levels assessed by oligonucleotide microarray analysis and quantitative realtime RT-PCR - how well do they correlate? BMC Genomics 2005, 6:59.

20. Dickins RA, Hemann MT, Zilfou JT, Simpson DR, Ibarra I, Hannon GJ, Lowe SW: Probing tumor phenotypes using stable and regulated synthetic microRNA precursors. Nat Genet 2005, 37:1289-1295.

21. Beesley AH, Weller RE, Senanayake S, Welch M, Kees UR: Receptor mutation is not a common mechanism of naturally occurring glucocorticoid resistance in leukaemia cell lines. Leuk Res 2009, 33:321-325.

22. Heerema NA, Sather HN, Sensel MG, Kraft P, Nachman JB, Steinherz PG, Lange BJ, Hutchinson RS, Reaman GH, Trigg ME, et al: Frequency and clinical significance of cytogenetic abnormalities in pediatric T-lineage acute lymphoblastic leukemia: a report from the Children's Cancer Group. J Clin Oncol 1998, 16:1270-1278.

23. Dou Y, Hess JL: Mechanisms of transcriptional regulation by MLL and its disruption in acute leukemia. Int J Hematol 2008, 87:10-18.

24. Krivtsov AV, Armstrong SA: MLL translocations, histone modifications and leukaemia stem-cell development. Nat Rev Cancer 2007, 7:823-833.

25. Kaspers GJ, Wijnands JJ, Hartmann R, Huismans L, Loonen AH, Stackelberg A, Henze G, Pieters R, Hahlen K, Van Wering ER, Veerman AJ: Immunophenotypic cell lineage and in vitro cellular drug resistance in childhood relapsed acute lymphoblastic leukaemia. Eur J Cancer 2005, 41:1300-1303.

26. Klumper $E$, Pieters $R$, Veerman AJ, Huismans DR, Loonen AH, Hahlen $\mathrm{K}$, Kaspers GJ, van Wering ER, Hartmann R, Henze G: In vitro cellular drug resistance in children with relapsed/refractory acute lymphoblastic leukemia. Blood 1995, 86:3861-3868.

27. Nagayama J, Tomizawa D, Koh K, Nagatoshi Y, Hotta N, Kishimoto T, Takahashi Y, Kuno T, Sugita K, Sato T, et al: Infants with acute lymphoblastic leukemia and a germline MLL gene are highly curable with use of chemotherapy alone: results from the Japan Infant Leukemia Study Group. Blood 2006, 107:4663-4665.

28. Tonko M, Ausserlechner MJ, Bernhard D, Helmberg A, Kofler R: Gene expression profiles of proliferating vs. G1/G0 arrested human leukemia cells suggest a mechanism for glucocorticoid-induced apoptosis. FASEB J 2001, 15:693-699.

29. Liu H, Cheng EH, Hsieh JJ: Bimodal degradation of MLL by SCFSkp2 and APCCdc20 assures cell cycle execution: a critical regulatory circuit lost in leukemogenic MLL fusions. Genes Dev 2007, 21:2385-2398. 
30. Vander Heiden MG, Cantley LC, Thompson CB: Understanding the Warburg effect: the metabolic requirements of cell proliferation. Science 2009, 324:1029-1033.

31. Tyagi S, Herr W: E2F1 mediates DNA damage and apoptosis through HCF-1 and the MLL family of histone methyltransferases. EMBO J 2009, 28:3185-3195.

32. Stam RW, Hubeek I, den Boer ML, Buijs-Gladdines JG, Creutzig U, Kaspers GJ, Pieters R: MLL gene rearrangements have no direct impact on Ara-C sensitivity in infant acute lymphoblastic leukemia and childhood M4/M5 acute myeloid leukemia. Leukemia 2006, 20:179-82.

33. Ramakers-van Woerden NL, Pieters R, Rots MG, van Zantwijk CH, Noordhuis P, Beverloo HB, Peters GJ, van Wering ER, Camitta BM, Pui CH, et al: Infants with acute lymphoblastic leukemia: no evidence for high methotrexate resistance. Leukemia 2002, 16:949-951.

34. Lawlor ER, Soucek L, Brown-Swigart L, Shchors K, Bialucha CU, Evan Gl: Reversible kinetic analysis of Myc targets in vivo provides novel insights into Myc-mediated tumorigenesis. Cancer Res 2006, 66:4591-4601.

35. Schmidt S, Rainer J, Riml S, Ploner C, Jesacher S, Achmuller C, Presul E, Skvortsov S, Crazzolara R, Fiegl M, et al: Identification of glucocorticoidresponse genes in children with acute lymphoblastic leukemia. Blood 2006, 107:2061-2069.

36. Rozovskaia T, Ravid-Amir O, Tillib S, Getz G, Feinstein E, Agrawal H, Nagler A, Rappaport EF, Issaeva I, Matsuo Y, et al: Expression profiles of acute lymphoblastic and myeloblastic leukemias with ALL-1 rearrangements. Proc Natl Acad Sci USA 2003, 100:7853-7858.

37. Kotani A, Ha D, Hsieh J, Rao PK, Schotte D, den Boer ML, Armstrong SA, Lodish HF: miR-128b is a potent glucocorticoid sensitizer in MLL-AF4 acute lymphocytic leukemia cells and exerts cooperative effects with miR-221. Blood 2009, 114:4169-4178.

38. Webb JC, Golovleva I, Simpkins AH, Kempski H, Reeves B, Sturt N, Chessells JM, Brickell PM: Loss of heterozygosity and microsatellite instability at the MLL locus are common in childhood acute leukemia, but not in infant acute leukemia. Blood 1999, 94:283-290.

39. Raimondi SC, Frestedt JL, Pui CH, Downing JR, Head DR, Kersey JH, Behm FG: Acute lymphoblastic leukemias with deletion of $11 q 23$ or a novel inversion (11)(p13q23) lack MLL gene rearrangements and have favorable clinical features. Blood 1995, 86:1881-1886.

40. Takeuchi S, Cho SK, Seriu T, Koike M, Bartram CR, Reiter A, Schrappe M, Takeuchi C, Taguchi H, Koeffler HP: Identification of three distinct regions of deletion on the long arm of chromosome 11 in childhood acute lymphoblastic leukemia. Oncogene 1999, 18:7387-7388.

41. Whitman SP, Liu S, Vukosavljevic T, Rush L, Yu L, Liu C, Klisovic Ml, Maharry K, Guimond M, Strout MP, et al: The MLL partial tandem duplication: evidence for recessive gain-of-function in acute myeloid leukemia identifies a novel patient subgroup for molecular-targeted therapy. Blood 2005, 106:345-352.

42. Cerveira N, Santos J, Bizarro S, Costa V, Ribeiro FR, Lisboa S, Correia C, Torres L, Vieira J, Snijder S, et al: Both SEPT2 and MLL are down-regulated in MLL-SEPT2 therapy-related myeloid neoplasia. BMC Cancer 2009, 9:147.

43. Kubicka M, Soszynska K, Mucha B, Rafinska B, Kolodziej B, Haus O, Styczynski J: Unusual profiles of pediatric acute lymphoblastic leukemia with MLL gene rearrangement. Leuk Lymphoma 2007, 48:2083-2086.

44. Wiederschain D, Kawai $H$, Shilatifard A, Yuan ZM: Multiple mixed lineage leukemia (MLL) fusion proteins suppress p53-mediated response to DNA damage. J Biol Chem 2005, 280:24315-24321.

45. Eguchi M, Eguchi-Ishimae M, Knight D, Kearney L, Slany R, Greaves M: MLL chimeric protein activation renders cells vulnerable to chromosomal damage: An explanation for the very short latency of infant leukemia. Genes Chromosomes Cancer 2006, 45:754-760.

46. Liu H, Takeda S, Kumar R, Westergard TD, Brown EJ, Pandita TK, Cheng EH, Hsieh JJ: Phosphorylation of MLL by ATR is required for execution of mammalian S-phase checkpoint. Nature 2010, 467:343-6.

doi:10.1186/1476-4598-9-284

Cite this article as: Beesley et al:: Influence of wild-type MLL on glucocorticoid sensitivity and response to DNA-damage in pediatric acute lymphoblastic leukemia. Molecular Cancer 2010 9:284.

\section{Submit your next manuscript to BioMed Central and take full advantage of:}

- Convenient online submission

- Thorough peer review

- No space constraints or color figure charges

- Immediate publication on acceptance

- Inclusion in PubMed, CAS, Scopus and Google Scholar

- Research which is freely available for redistribution

Submit your manuscript at www.biomedcentral.com/submit 